\title{
Marx: da Crítica da Economia Política às Bases da Teoria da História
}

Ugo Rivetti

\section{Resumo:}

O presente texto procura analisar a constituição da teoria da História de Marx - qualificada como "materialismo histórico" - com atenção especial para a formulação desta teoria exposta n'A Ideologia Alemã, procurando enfatizar o papel da crítica dos conceitos da Economia Política empreendida por Marx, especialmente da categoria de divisão do trabalho, para a elaboração das linhas gerais dessa teoria.

Palavras-chave: Economia Política - teoria materialista da História divisão do trabalho. 


\section{A Crítica à Economia Política: dos Manuscritos de 1844 à Ideologia Alemã}

Há um consenso entre os marxólogos de tomar o ano de I844 como aquele no qual se deu o primeiro contato de Marx com a Economia Política. Segundo a Chronologie de Marx, de Maximilien Rubel (considerado por muitos como o maior dos marxólogos), entre abril e junho de I844, Marx se dedicou à leitura das obras de um grupo extenso e heterogêneo de teóricos da economia, entre os quais se destacam Adam Smith, David Ricardo, James Mill, MacGulloch, Boisguillebert, Jean-Baptiste Say, Skarbek, S. Sismondi, E. Buret e W. Schulz. ' É possível afirmar que, a partir de I844, os estudos de Economia Política permaneceriam como uma das preocupações teóricas centrais de Marx. No entanto, não é apenas esse interesse que se manifesta em toda sua trajetória subsequente a I844. O posicionamento que Marx assume em relação a esses autores e a suas conclusões tornar-se-ia um dos traços distintivos de seu trabalho intelectual. Não se tratava para ele somente de realizar um empreendimento restrito à exposição do sistema da Economia burguesa. Ao contrário, o principal esforço de Marx consistia em efetuar a crítica das categorias teóricas mobilizadas pela Economia Política ao longo de sua exposição. ${ }^{2}$ Nas palavras de Jorge Grespan: "A exposição é crítica, porque mostra, sob a nova ordem das categorias no pensamento de Marx, como a anterior, dos clássicos, foi desmontada e remontada a partir de uma inversão ou alteração radical no significado de conceitos fundamentais". ${ }^{3}$ A inovação empreendida por Marx consistiu em estabelecer uma "nova ordem das categorias", o que implicava não apenas redefinir o conteúdo das categorias, mas também em redesenhar o horizonte intelectual no qual elas deveriam ser posicionadas, isto é, modificar as questões de fundo que justificavam a mobilização dessas categorias.

O resultado desses estudos pode ser inicialmente vislumbrado nos Manuscritos Econômico-Filosóficos, escritos entre abril e agosto de I844, nos quais Marx analisa questões centrais da Economia Política clássica sob um ponto de vista totalmente novo. É nos Manuscritos que Marx expõe de maneira crítica as categorias e conclusões da Economia Política, identificando como traço distintivo da sociedade burguesa o trabalho alienado.

No entanto, apesar da importância dos Manuscritos no todo da obra marxiana, somente n'A Ideologia Alemã essa crítica da Economia Política seria articulada ao

I cf. Maximilien Rubel. Ouvres I Economie. Paris: Gallimard, I965.

$2 c f$. Jorge Grespan. "A Grise na Grítica à Economia Política”. In: Crítica Marxista (2000): pp. 77-97.

3 idem. ib. p. 78. 
projeto já mencionado de recolocar as categorias da Economia Política em um novo horizonte intelectual pautado por uma teoria mais abrangente e por questões que superavam o âmbito da Economia Política. Embora esses estudos fossem posteriormente associados ao projeto de Marx de elaborar, para usar os termos de Engels em carta a Marx, a "sua Economia"4 - projeto que somente seria iniciado como tal em $185 \mathrm{I}^{5}$ - eles se inserem, n'A Ideologia Alemã, em um projeto intelectual mais amplo e ambicioso. Segundo David McLellan, a preocupação permanente de Marx em estudar e submeter à crítica as conclusões dos economistas clássicos se devia primordialmente à sua intenção de compreender três questões para ele centrais: os mecanismos de funcionamento da sociedade capitalista, os fatores determinantes do processo histórico geral e as possibilidades de emancipação proletária. ${ }^{6}$ Tratava-se, portanto, de um projeto teórico não apenas preocupado em analisar uma formação histórica particular (a sociedade mercantil capitalista), mas que intencionava formular novas questões inseridas em um novo horizonte intelectual. Um projeto que ambicionava se converter em uma teoria da História (do processo histórico geral) apoiada em eixos políticos claros (a emancipação proletária).

\section{Os Três Eixos da Teoria}

Nesse sentido, o que Marx colocava em evidência era a formulação de uma teoria da História, no interior da qual estariam articulados aqueles três eixos, sociedade capitalista, processo histórico geral e emancipação proletária. Teoria original em um duplo sentido: primeiro, no de não se limitar à abordagem de uma única formação social (a mercantil capitalista), mas de tratar do processo histórico como totalidade; segundo, no de se orientar por um princípio político, a emancipação proletária. A primeira dimensão de originalidade dessa teoria da História é expressa justamente como aquilo que falta à concepção de História dos jovens hegelianos, em uma passagem que revela o tom adota por Marx e Engels n’A Ideologia Alemã.

"e, quando eles próprios [os teóricos idealistas, pretensos herdeiros de Hegel] se entregam a fazer construções históricas, saltam com a maior pressa por sobre todos os períodos precedentes, passando de imediato da 'civilização mongol' para

4 Roman Rosdolsky. Gênese e Estrutura de O Capital. Rio de Janeiro: Editora UERJ e Contraponto, 200 I. 5 idem. ib. p. 22.

6 Para uma análise detalhada da trajetória intelectual de Marx, cf. David McLellan. Karl Marx: His Life and Thought. Hong Kong: Papermac, I987. 
a história propriamente 'plena de conteúdo', sobretudo a história dos Hallische e dos Deutsche Jahrbücher e para a dissolução da escola hegeliana numa discórdia geral. Todas as outras nações, todos os acontecimentos reais são esquecidos, o teathrum mundi limita-se à feira de livros de Leipzig e às controvérsias recíprocas da 'Crítica', do 'Homem' e do 'Único'”.?

Como a passagem revela, havia n'A Ideologia um permanente debate entre Marx e os jovens hegelianos (especialmente Max Stirner e Bruno Bauer). Assim, não se tratava apenas de propor uma nova forma de conceber o movimento histórico, considerando "todas as nações", "todos os acontecimentos reais", "o teahrum mundi”. A tarefa consistia, também, em contrapor essa nova concepção à idealista, até então predominante na Alemanha. Partindo da crítica das concepções idealistas da História, elaborar uma nova concepção que pudesse se estabelecer como uma formulação alternativa capaz de articular um discurso novo. Impunha-se desqualificar a concepção idealista que promovia a separação das ideias de seus produtores, autonomizando-as como "autodeterminações do conceito". ${ }^{8}$ Impunha-se, em suma, demonstrar com base em argumentos lógicos e históricos de que modo as ideias estão vinculadas aos indivíduos e às "relações que nascem de um dado estágio do modo de produção"; ${ }^{9}$ de que modo as ideias são "a expressão ideal das relações materiais dominantes, são as relações materiais (...) apreendidas como ideias". ${ }^{10}$ A concepção de História a ser formulada, portanto, deveria tomar como referência as "forças produtivas existentes", a "base real da História" considerada em "conexão com o fluxo histórico".

"Essa concepção de História consiste, portanto, em desenvolver o processo real de produção a partir da produção material da vida imediata e em conceber a forma de intercâmbio conectada a esse modo de produção e por ele engendrada, quer dizer, a sociedade civil em seus diferentes estágios, como o fundamento de toda História, tanto a apresentação em sua ação como Estado como explicando a partir dela o conjunto das diferentes criações teóricas e formas de consciência - religião, filosofia, moral etc. etc.” ${ }^{\text {II }}$

Tarefa dupla: partir da base real da História, mas sempre a considerando em conexão com o fluxo histórico. Para a primeira tarefa, impunha-se considerar as

\footnotetext{
7 Karl Marx e Friedrich Engels. A Ideologia Alemã. São Paulo: Boitempo Editorial, 2007, p. 45.

8 Idem. ib. p. 50 .

9 Idem. ib. p. 49.

IO Idem. ib. p. 47.

II Idem. ib. p. 42 .
} 
forças produtivas existentes; para a segunda, o motor da História, a "formação de uma massa revolucionária”. Embora apresentadas aqui separadamente, as duas tarefas estavam diretamente relacionadas no interior do projeto teórico de Marx, constituindo os eixos em torno dos quais ele viria a elaborar sua teoria da História.

A formação de uma massa revolucionária, é verdade, dependia da formação de uma consciência revolucionária, uma consciência comunista. Mas o potencial revolucionário único do proletariado residia na sua condição particular de classe. Nas palavras do próprio Marx: "A classe revolucionária, por já se defrontar desde o início com uma classe, surge não como classe, mas sim como representante de toda a sociedade". ${ }^{12}$ Em outras palavras, tanto a base real da História como seu fluxo estão apoiados nas forças produtivas dadas. Uma teoria da História que emerge como teoria do processo histórico como totalidade deve, portanto, partir da análise da base que sustenta a ação da classe capacitada a modificar o curso histórico, isto é, das condições materiais, das forças produtivas dadas pela História, análise fornecida, justamente, pela Economia Política.

\section{Incorporação e Redefinição da Categoria de Divisão do Trabalho}

O nascimento da Economia Política está associado a um grupo particular de pensadores, os fisiocratas. Sob a liderança de François Quesnay (I694I774), os fisiocratas prepararam o terreno para a consolidação da Economia como disciplina acadêmica autônoma. Sua maior contribuição consistiu em redefinir a fonte da riqueza, não mais como o acúmulo de metais preciosos (como propunham os mercantilistas), mas como elemento dependente da produtividade do trabalho. Apoiando-se nessa contribuição, Adam Smith amplia-a, identificando os aprimoramentos na capacidade produtiva do trabalho à fonte do aumento de riqueza e concebendo esses aprimoramentos como produto da divisão do trabalho. ${ }^{13}$ A divisão do trabalho explicaria o incremento da produtividade do trabalho característico dos tempos modernos na medida em que, ao vincular o trabalhador a uma única operação, permitiria: I) o aumento da destreza desse trabalhador na execução de sua tarefa, 2) a redução do tempo despendido na passagem de uma operação para outra e 3) o uso combinado de máquinas que permitiria a um único operador realizar o trabalho de muitos.

I2 Idem. ib. pp. 48-49.

I3 S. Zamagni. Microeconomic Theory: an introduction. Oxford: Blackwell, I987, p. IO. 
Marx incorpora esse conceito de divisão do trabalho, primeiramente elaborado pela Economia Política, redefinindo-o no interior de seu próprio projeto teórico. No esquema de Smith a categoria de divisão do trabalho aparecia como um recurso teórico privilegiado para compreender a economia capitalista e as leis motoras básicas que governariam as suas operações; em suma, para explicar o modus operandi de um tipo particular de economia, a mercantil capitalista. Já no esquema elaborado por Marx n’A Ideologia, a divisão do trabalho aparece como o eixo teórico em torno do qual se estrutura a sua concepção de História, como o fenômeno histórico real capaz de explicar o processo histórico em sua totalidade, na medida em que permitiria explicar a sucessão dos diferentes modos de produção com os respectivos níveis de desenvolvimento de suas forças produtivas ao longo da História. Nesse sentido, a proposição de Marx é clara: "o grau de desenvolvimento das forças produtivas de uma nação é indicado, do modo mais claro, pelo grau de desenvolvimento a que chegou a divisão do trabalho". ${ }^{14}$

Até então, os principais nomes da Economia Política tinham dado atenção especial ao trabalho como o meio pelo qual se dá a vinculação do homem com a natureza, meio pelo qual o homem modifica a natureza e cria, a partir dessa modificação, valor - seja apenas nas atividades agrícolas, como afirmavam os fisiocratas, seja para qualquer atividade na qual houvesse dispêndio de trabalho humano, como propunha Smith. O que Marx colocava em evidência n'A Ideologia era outro aspecto do trabalho; não o trabalho como atividade humana básica que impõe o domínio do homem sobre a natureza, mas como a atividade que sujeita os próprios homens, que transformam as "forças (relações) pessoais em forças reificadas"; ${ }^{15}$ que tornam as relações do "processo real de vida" dos homens em relações autônomas em relação a eles; que tornam os poderes dos homens, superiores a eles próprios. Assim, aparece não o trabalho simplesmente, mas a divisão do trabalho, a sujeição do homem a um mecanismo, separado e autônomo.

\footnotetext{
"Esse fixar-se da atividade social, essa consolidação de nosso próprio produto num poder objetivo situado acima de nós, que foge ao nosso controle, que contraria nossas expectativas e aniquila nossas conjeturas, é um dos principais momentos no desenvolvimento histórico até aqui realizado. O poder social, isto é, a força de produção multiplicada que nasce da cooperação dos diversos indivíduos condicionada pela divisão do trabalho, aparece a esses indivíduos, (...), não como seu próprio poder unificado, mas sim como uma potência estranha, situada fora deles, sobre a qual não
}

I4 Karl Marx e Friedrich Engels. A Ideologia Alemã. op. cit., p. I8.

I5 Idem. ib. p. 64 . 
sabem de onde veio nem para onde vai, uma potência, portanto, que não podem mais controlar (...)."

Mas essa é uma "fixação da atividade social" que não se restringe ao modo capitalista. Baseada em um primeiro momento na "divisão natural do trabalho na família e na separação da sociedade em diversas famílias opostas umas às outras", ${ }^{17}$ a divisão do trabalho impõe a "distribuição desigual (...) do trabalho e de seus produtos", ${ }^{18}$ estabelecendo, assim, a propriedade. Sociedade livre da divisão do trabalho é aquela livre da propriedade privada ou, sociedade sem propriedade privada é aquela sem divisão do trabalho.

Ao articular desse modo as noções de propriedade privada e divisão do trabalho, Marx estabelece um ponto de ruptura em relação à tradição da Economia Política clássica. Como ele afirma nos Manuscritos, não basta partir do fato da propriedade privada; é necessário considerá-la em função do processo material por meio do qual a propriedade privada se efetiva, reconhecendo na propriedade privada não uma circunstância acidental, mas a expressão de um desenvolvimento necessário. ${ }^{19}$ Tomando como ponto de partida "as premissas da Economia Política", aceitando "sua linguagem e suas leis", Marx toma os conceitos de propriedade privada e divisão do trabalho do sistema da Economia Política burguesa, mas redefine ambos ao estabelecer uma nova relação entre eles. No esquema marxiano, a propriedade privada deixa de ser um dado, surgindo como um fenômeno histórico que deriva da divisão do trabalho. Isso porque, "com a divisão do trabalho, [...], estão dadas ao mesmo tempo a distribuição e, mais precisamente, a distribuição desigual, tanto quantitativa quanto qualitativamente, do trabalho e de seus produtos". ${ }^{20}$ Assim, a divisão do trabalho coloca em evidência não apenas a distribuição desigual do trabalho e de seus produtos (a qual engendra a propriedade privada), mas também a relação direta existente entre o trabalhador e a produção. ${ }^{21}$ Ao longo de seu desenvolvimento, a divisão do trabalho aprofunda os vínculos funcionais entre a esfera da produção e do intercâmbio. A vinculação funcional entre essas duas esferas atinge seu ápice na economia mercantil capitalista, na qual o produtor individual isolado deve levar em consideração as decisões dos demais produtores,

I6 Idem. ib. p. 38.

I7 Idem, ib. p. 36 .

I8 Ibidem.

I9 Karl Marx. "Economic and Philosophical Manuscripts". In: Early Writings. London: Penguin Books, I992, p. 322 .

20 Karl Marx e Friedrich Engels. A Ideologia Alemã. op.cit. p. 36.

2I Karl Marx. "Economic and Philosophical Manuscripts". In: Early Writings. op. cit. p. 325. 
uma vez que seu produto, quando finalizado, deverá ser lançado no mercado, para ser vendido e para que seu valor seja realizado e retorne ao produtor na forma de dinheiro.

\section{Constituição da Teoria da História}

O que Marx coloca, portanto, em foco, é a divisão do trabalho tanto como um fenômeno de natureza histórica que condiciona o fluxo histórico quanto como a categoria que estrutura sua teoria do fluxo histórico. A teoria materialista da História exposta n'A Ideologia, ainda que de forma mais polêmica do que sistemática, propõe uma sucessão dos modos de produção apoiada no grau de desenvolvimento da divisão do trabalho. O modelo histórico da sucessão de modos de produção concebe o fluxo histórico como a crescente emancipação do homem em relação à natureza e da capacidade humana de controlá-la. Desse modo, a divisão do trabalho adquire um estatuto superior na teoria da História de Marx, na medida em que "A força motriz da História, (...), é dúplice, constituída pelas relações de trabalho e pela organização global da sociedade”. ${ }^{22}$ Com a divisão do trabalho se processa a conjugação de ambas, na medida em que ela consiste em uma divisão social do trabalho, qualificação essa que adquire sentido novo na sociedade mercantil capitalista. Nesta, a divisão social do trabalho determina o aparecimento de produtores individuais de mercadorias independentes uns dos outros, portanto, determina a divisão de operações de trabalho no processo de produção global da sociedade. Já a divisão técnica do trabalho define a divisão das operações que compõem o próprio processo de trabalho, determinando sua distribuição entre os trabalhadores assalariados.

Nesse sentido, é na economia mercantil capitalista que a divisão do trabalho submete da forma mais profunda os homens, agora trabalhadores, àquela "potência estranha, situada fora deles" que percorre "uma sequência particular de fases e etapas de desenvolvimento, independente do querer e do agir dos homens". Passando por sucessivas fases de desenvolvimento (cooperação, manufatura e grande indústria), a divisão do trabalho amplia a exploração da massa de trabalhadores por meio da apropriação de forças suplementares pelo capital (trabalho feminino e infantil), prolonga a jornada de trabalho e intensifica o trabalho até o limite físico dos trabalhadores. A divisão do trabalho na economia mercantil capitalista consolida a "subordinação formal do trabalho

22 Lawrence Krader. "Evolução, Revolução e Estado: Marx e o Pensamento Etnológico”. In: História do Marxismo, v.I. São Paulo: Paz e Terra, I983, p. 300. 
ao capital", ${ }^{23}$ convertendo-a em subordinação real. Essa subordinação real atinge sua forma mais completa com a grande indústria, quando o processo de produção deixa de ter como fim a produção de mercadorias, substituindo-o pelo fim de extrair uma quantidade sempre maior de mais-valia. $O$ processo de produção deixa de ser conduzido pelo processo de trabalho que gera mercadorias, passando a se orientar pelo processo de valorização do valor.

Ao analisar desse modo a configuração da sociedade capitalista apoiada em uma divisão do trabalho cada vez mais sofisticada - não mais simplesmente divisão social, mas também, e principalmente, divisão técnica - Marx retoma sua concepção de um fluxo histórico que culminaria com uma revolução de proporções únicas, concepção que se apoia na evidência de que

"Cada nova classe instaura sua dominação somente sobre uma base mais ampla do que a da classe que dominava até então, enquanto, posteriormente, a oposição das classes não-dominantes contra a classe então dominante torna-se cada vez mais aguda e mais profunda”. ${ }^{24}$

\section{A Possibilidade da Emancipação}

Para Marx, o momento decisivo do processo histórico teria sido viabilizado apenas com a grande indústria. Ao revolucionar o meio de trabalho, convertendo a ferramenta em máquina, a grande indústria converte as ferramentas e os aparelhos antes manipulados pelo trabalhador da manufatura em ferramentas de um mecanismo independente. O resultado final é a constituição de um "sistema articulado de máquinas de trabalho individuais de diferentes espécies", ${ }^{25}$ um mecanismo autônomo em relação aos trabalhadores e cujo funcionamento perfeito depende da continuidade de seu processo global. A máquina produzida pela grande indústria permite essa continuidade, uma vez que o próprio mecanismo leva de uma fase de produção à seguinte. Assim, processa a passagem de uma divisão do trabalho apoiada no isolamento dos processos particulares por uma divisão baseada na continuidade dos processos particulares. Para o trabalhador, essa nova configuração estabelecida pela grande indústria "torna insuportável (...) não apenas a relação com o capitalista, mas sim o próprio trabalho". ${ }^{26}$

23 Karl Marx. O Gapital. v. II. São Paulo: Nova Cultural, I988, p. IO2.

24 Karl Marx e Friedrich Engels. A Ideologia Alemã. op. cit. p. 49.

25 Karl Marx. O Capital. op. cit. p. II.

26 Karl Marx e Friedrich Engels. A Ideologia Alemã. op. cit. p. 6I. 
Há um elemento comum que liga essa fase de desenvolvimento econômico (grande indústria) às fases anteriores. O que se manifesta nessa fase "avançada" do desenvolvimento capitalista é algo que já estava presente em fases anteriores, isto é, que o produto que o trabalho produz aparece ao produtor (seja para o produtor coletivo na grande indústria, seja para o produtor individual nas fases anteriores) como um poder independente dele, como um "objeto alienado". O desenvolvimento da fase capitalista leva esse fenômeno às últimas consequências, instituindo uma relação inversamente proporcional entre a condição do trabalhador e o poder e a extensão de sua produção; entre a miséria do trabalhador e o poder e volume de sua produção. ${ }^{27}$ Essa relação inversa é reforçada pelo desenvolvimento da divisão do trabalho, por meio do qual o produto gerado pelo processo de trabalho deixa de ser "produto direto do produtor individual" em produto do produtor social, "em produto comum de um trabalhador coletivo, isto é, de um pessoal combinado de trabalho". ${ }^{28}$ Para ingressar no processo de trabalho, impõe-se ao trabalhador a necessidade de se converter em "órgão do trabalhador coletivo".

A divisão do trabalho contribui de forma decisiva para o aprofundamento dessa relação alienada do trabalhador para com seu trabalho e finalmente, na grande indústria, para com sua atividade de trabalho. Como essa seria, segundo o argumento de Marx, uma relação de proporções históricomundiais, independente de diferenças de nacionalidade, a divisão do trabalho engendraria a constituição de uma classe que reconhece em suas condições de vida, em seu trabalho e no "conjunto das condições de existência da sociedade" apenas elementos acidentais sobre os quais ela não exerce nenhum controle. Uma classe cujos membros, os proletários, para afirmar a si mesmos como pessoas, têm de suprassumir sua própria condição de existência anterior, que é, ao mesmo tempo, a condição de toda a sociedade anterior, isto é, o trabalho. ${ }^{29}$

\section{Conclusão}

Esta é, em linhas gerais, a teoria da História de Marx. Nela, a divisão do trabalho não aparece apenas como o mecanismo responsável pelo incremento da produção, como no esquema da Economia Política clássica. Ela se converte na categoria que conjuga os três eixos que orientam a reflexão de Marx,

27 Cf. Karl Marx. "Economic and Philosophical Manuscripts". In: Early Writings. op. cit. p. 322.

28 Karl Marx. O Capital. op. cit. p. IOI.

29 "Karl Marx e Friedrich Engels. A Ideologia Alemã. op. cit. p. 66. 
estrutura a teoria histórica de Marx e vincula-a a uma teoria da sociedade capitalista, na medida em que indica a sucessão dos modos de produção, ao determinar o grau de desenvolvimento das forças produtivas, o modo pelo qual a sociedade capitalista se estrutura e o modo pelo qual essa estruturação viabiliza a revolução empreendida pelo proletariado, revolução que emancipa o proletariado. Partindo da identificação dos fatores determinantes do processo histórico geral - a divisão do trabalho e as forças produtivas - Marx elabora uma teoria dos mecanismos de funcionamento da sociedade capitalista - divisão social e técnica do trabalho, manufatura e grande indústria - demonstrando de que modo aqueles fatores determinantes do processo histórico geral, levados à última potência no capitalismo, seriam revolucionados por uma classe cuja emancipação somente pode se realizar em termos histórico-mundiais e que significa a emancipação de toda a humanidade. Uma classe cuja emancipação depende da subsunção das forças reificadas produzidas pela divisão do trabalho e da sua reconversão em relações pessoais; emancipação que depende da superação da divisão do trabalho.

\section{Referências Bibliográficas}

GRESPAN, Jorge. "A Crise na Crítica à Economia Política". In: Crítica Marxista. n. ${ }^{\circ}$ IO, 2000, pp. 77- 97.

KRADER, Lawrence. "Evolução, Revolução e Estado: Marx e o Pensamento Etnológico". In: HOBSBAWM, Eric (org.). História do Marxismo, v. I. São Paulo: Paz e Terra, I983.

MARX, Karl; ENGELS, Friedrich. A Ideologia Alemã. São Paulo: Boitempo Editorial, 2007.

Early Writings. London: Penguin Books, I992.

O Capital. São Paulo: Nova Cultural, I988.

. Ouvres I Economie; editión établie et annotée par Maximilien Rubel. Paris: Gallimard, I965.

MGLELLAN, David. Karl Marx: His Life and Thought. Hong Kong: Papermac, I987. 
Marx: da Crítica da Economia Política às Bases da Teoria da História

ROSDOLSKY, Roman. Gênese e estrutura de O Capital de Karl Marx. Rio de Janeiro: Eduerj e Contraponto, 200I.

ZAMAGNI, S. Microeconomic Theory: an introduction. Oxford: Balckwell, I987.

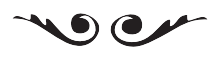

Ugo Rivetti é graduando em Ciências Sociais pela USP.

E-mail: ugo.rivetti@usp.br 